\title{
Quantitative T1-maps delineate myocardium at risk as accurately as T2-maps - experimental validation with microspheres
}

\author{
Martin Ugander ${ }^{\text {*}}$, Paul S Bagi ${ }^{1}$, Abiola J Oki ${ }^{1}$, Billy Chen ${ }^{1}$, Li-Yueh Hsu', Anthony H Aletras ${ }^{1}$, Saurabh Shah², \\ Andreas Greiser ${ }^{3}$, Peter Kellman ${ }^{1}$, Andrew E Arai ${ }^{1}$
}

From 2011 SCMR/Euro CMR Joint Scientific Sessions

Nice, France. 3-6 February 2011

\section{Introduction}

Clinical quantitative T1 and T2 mapping sequences are available, but it is unclear which, if either, is more accurate for determining myocardium at risk.

\section{Purpose}

To validate and determine the accuracy for using in vivo T1 mapping or T2 mapping for determining myocardium at risk, compared to blood flow quantification at coronary occlusion by microspheres.

\section{Methods}

Dogs $(\mathrm{n}=12)$ underwent coronary occlusion (2 hours), during which microspheres were injected into the left atrium, followed by reperfusion (4 hours). The entire left ventricle was imaged at $1.5 \mathrm{~T}$ (Siemens) in contiguous short-axis slices with a Modified Look-Locker Inversion-recovery sequence for T1 mapping (Messroghli, JMRI, 2007), and a T2-prepared SSFP sequence for T2 mapping (Giri, JCMR, 2009). Myocardium at risk was defined as regions in the left ventricle which had a T1 or $\mathrm{T} 2$ value greater than $2 \mathrm{SD}$ from remote. In four dogs, hearts were excised and blood flow $(\mathrm{ml} / \mathrm{min} / \mathrm{g})$ was determined by microsphere analysis in 16 sectors per short-axis slice for all short-axis slices in the left ventricle. Myocardium at risk was defined as regions in the left ventricle with a blood flow at occlusion less than 2SD from remote.

\section{Results}

Global myocardium at risk, expressed as percent of left ventricular mass (\%LVM), showed similar results for T1 mapping compared to T2 mapping ( $\mathrm{n}=12$, mean + /SD difference $1.5+/-4.0 \% \mathrm{LVM}, \mathrm{R} 2=0.86, \mathrm{p}<0.001)$. On a slice-by-slice basis $(n=4$ dogs, 34 slices), myocardium at risk was also similar for T1 and T2 mapping (difference $0.4+/-7.6 \%$ of slice, $R 2=0.96, \mathrm{p}<0.001$ ), T1 mapping corresponded to microsphere analysis (mean difference $2.0+/-12.8 \%$ of slice, $\mathrm{R} 2=0.90, \mathrm{p}<0.001$ ), and T2 mapping corresponded to microsphere analysis (mean difference $1.6+/-13.8 \%$ of slice, $\mathrm{R} 2=0.86$, $\mathrm{p}<0.001)$. Figure 1 .

\section{Conclusions}

When it comes to determining myocardium at risk after coronary ischemia and reperfusion, clinical non-contrast T1 mapping and T2 mapping sequences yield similar results, and both correspond excellently to microspheres. It appears that the relaxation properties $\mathrm{T} 1$ and T2 both change in a way which is consistent with the myocardial edema which occurs following myocardial ischemia/reperfusion.

\footnotetext{
Author details

${ }^{1}$ National Institutes of Health, Bethesda, MD, USA. ${ }^{2}$ Siemens Medical Solutions, Chicago, IL, USA. ${ }^{3}$ Siemens AG Healthcare Sector, Erlangen, Germany.
}

${ }^{1}$ National Institutes of Health, Bethesda, MD, USA

Full list of author information is available at the end of the article

C 2011 Ugander et al; licensee BioMed Central Ltd. This is an open access article distributed under the terms of the Creative Commons 


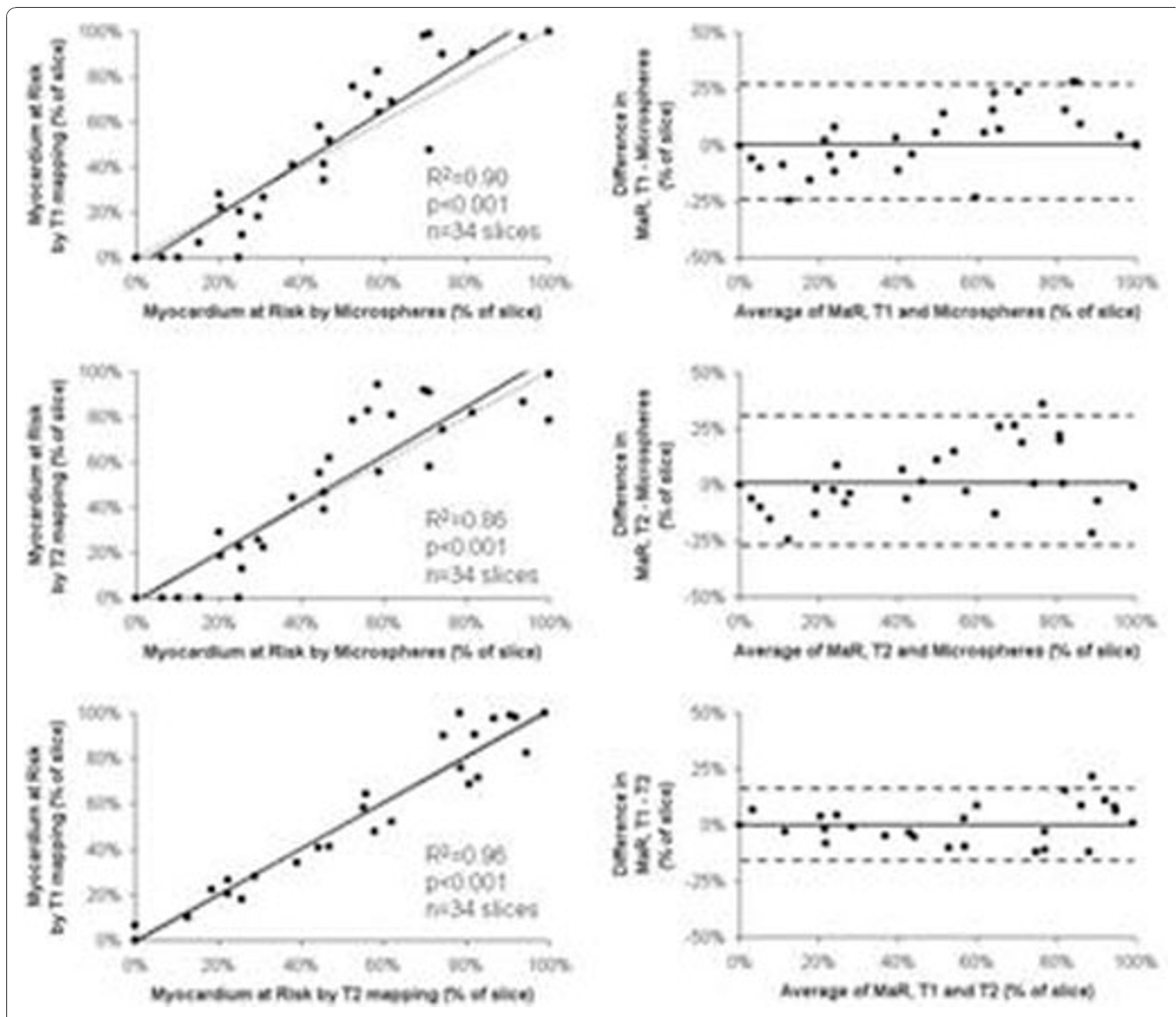

Figure 1 Linear regression (dashed line is line of identity) and Bland-Altman analysis (mean +/- 2SD) for myocardium at risk by T1 mapping vs. T2 mapping vs. microspheres.

Published: 2 February 2011

doi:10.1186/1532-429X-13-S1-062

Cite this article as: Ugander et al:: Quantitative T1-maps delineate myocardium at risk as accurately as T2-maps - experimental validation with microspheres. Journal of Cardiovascular Magnetic Resonance 201113 (Suppl 1):062.

\section{Submit your next manuscript to BioMed Central} and take full advantage of:

- Convenient online submission

- Thorough peer review

- No space constraints or color figure charges

- Immediate publication on acceptance

- Inclusion in PubMed, CAS, Scopus and Google Scholar

- Research which is freely available for redistribution 